\title{
Figurate Paraneoplastic Urticaria and Prostate Cancer
}

\author{
Adone Baroni, M.D., Ph.D., Franco Faccenda, M.D., Ph.D., Russo Teresa, M.D., \\ Vincenzo Piccolo, M.D.
}

Department of Dermatology, Second University of Naples, Napoli, Italy

\begin{abstract}
Dear Editor:
The term "Cutaneous Paraneoplastic Syndromes" refers to a group of skin disorders strongly associated with internal malignancies. Facultative paraneoplastic dermatoses are occassionally associated with cancer, while obligate paraneoplastic dermatoses certainly indicate its presence. Skin disorders in which association with a malignancy is possible, but extremely rare, are included in the first group, and urticaria is one of those ${ }^{1}$. Urticaria is most often reported with lymphoreticular system malignancies, rarely with lung cancer ${ }^{2}$, ovarian, rectum, bronchus ${ }^{3-5}$, and renal carcinoma ${ }^{6}$. We observed a 63-year-old man who presented with a six-month-history of unhealed, itchy, figurate (annular) chronic urticaria on his trunk and extremities (Fig. 1A, B). Differential diagnoses included erythema annulare centrifugum (EAC), erythema gyratum repens (EGR) and urticarial vasculitis (UV). EAC is an annular dermatosis characterized by erythematous papules spreading peripherally to form figurate lesions and centrally resolving, with a mild scaling of the inner aspect. It could be associated with infections, drugs, malignancies and other causes ${ }^{7}$ and was excluded because of the lack of its typical clinical features, as papules and scaling. EGR is considered an obligate paraneoplastic dermatosis, characterized by itchy concentric erythematous bands forming a typical wood-grain appearance, rapidly migrating and usually located on trunk and extremities ${ }^{8}$. The absence of
\end{abstract}

Received July 18, 2011, Revised August 30, 2011, Accepted for publication August 31, 2011

Corresponding author: Adone Baroni, M.D., Ph.D., Department of Dermatology, Second University of Naples, Via Pansini 5, 80131 Napoli, Italy. Tel: 39-0815666833, Fax: 39-0815468759, E-mail: adone.baroni@gmail.com

This is an Open Access article distributed under the terms of the Creative Commons Attribution Non-Commercial License (http:// creativecommons.org/licenses/by-nc/3.0) which permits unrestricted non-commercial use, distribution, and reproduction in any medium, provided the original work is properly cited. those clinical characteristics permitted us to rule out EGR. UV is a singular type of skin eruption, clinically resembling urticaria and histologically showing the characteristics of a leukocytoclastic vasculitis. It presents with wheals or erythematous plaques lasting for more than 24 hours in a fixed location, often associated with purpura, angioedema, photosensitivity, lymphadenopathy, arthralgia, fever, abdominal pain, dyspnea, and pleural and pericardial effusions ${ }^{9}$.

Both oral antihistamine and systemic and topical corticosteroid therapies were ineffective. The patient had no history of allergy and denied drug use. Laboratory findings (including routine blood examinations, complement $\mathrm{C} 3$ and C4, C1 inhibitor antigenic level, thyroid function test, antithyroid autoantibodies, antinuclear antibodies, rheumatoid factor, serum immunoglobulins level, circulating immune complexes, stool screening for blood, parasites and yeast, serum electrophoresis, enzyme-linked immunosorbent assay for specific anti-Helicobacter pylori immunoglobulin $G$ antibodies, anti-streptolysin $O$ titre, renal and liver function, total immunoglobulin $\mathrm{E}$ (IgE) level, and prick-test) were unremarkable. X-ray studies, including chest, dental and sinus series were also negative. Further investigations showed an increased prostate-specific antigen level. Multiple prostate biopsies revealed the presence of a histologically confirmed prostate adenocarcinoma. Total body computed tomography scans did not reveal metastases. The patient underwent a radical prostatectomy, and after a few weeks, urticaria spontaneously disappeared for the first time in six months. In the two years following prostatectomy no new episode of urticaria reappeared, and the patient is currently being monitored. Pathogenetic mechanisms are not known, but we hypothesize an immunological reaction induced by the presence of a malignant tumour. This case, based on exclusion diagnostic criteria and chronological relationships, represents the first case of urticaria associated with prostate cancer and emphasizes the importance of scru- 

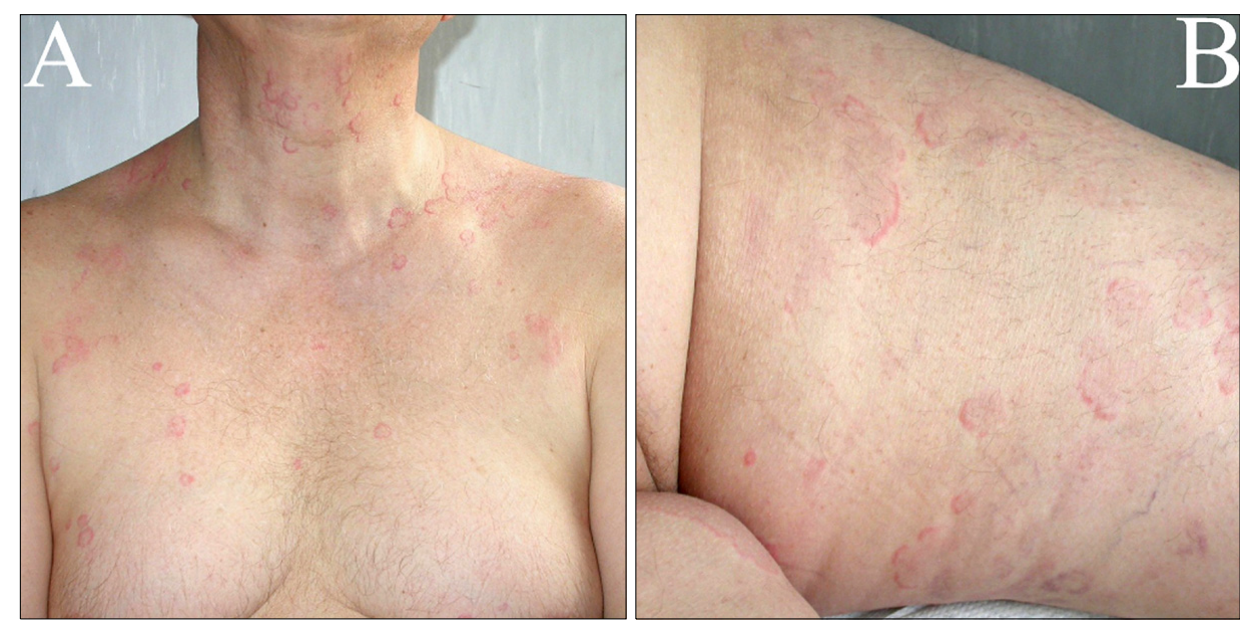

Fig. 1. (A) Figurate urticaria of trunk. (B) Figurate urticaria of extremities. pulous screening in all patients with chronic urticaria, especially when the specific therapies are ineffective.

\section{REFERENCES}

1. Newbold PC. Skin markers of malignancy. Arch Dermatol 1970;102:680-692.

2. De $P$, Abbasi $R$, Senadhira $T$, Orr $P$, Ullah A. Urticaria and large cell undifferentiated carcinoma of lung. Dermatol Online J 2005;11:45.

3. Reinhold U, Bruske T, Schupp G. Paraneoplastic urticaria in a patient with ovarian carcinoma. J Am Acad Dermatol 1996;35:988-989.
4. Urbach E. Endogenous allergy. Arch Dermat 194;45:697-722.

5. Hills EA. Adenocarcinoma of the bronchus with Cushing's syndrome, carcinoid syndrome, neuromyopathy and urticaria. Br J Dis Chest 1968;62:88-92.

6. Ducarme G, Rey D, Bryckaert PE, Reguiai Z, Bernard P, Staerman F. Paraneoplastic urticarial vasculitis and renal carcinoma. Prog Urol 2003;13:495-497.

7. McCleskey PE, Sarasua J. Erythematous, annular, scaling patches on the skin. Erythema annulare centrifugum. Am Fam Physician 2011;83:307.

8. Eubanks LE, McBurney E, Reed R. Erythema gyratum repens. Am J Med Sci 2001;321:302-305.

9. Poonawalla T, Kelly B. Urticaria: a review. Am J Clin Dermatol 2009;10:9-21. 